\title{
Estimación de áreas quemadas de los incendios en la provincia de Córdoba durante agosto de 2020 utilizando imágenes multiespectrales.
}

\author{
Estimation of burned areas from fires in the province of Córdoba during August 2020 \\ using multispectral images.
}

Presentación: 6-7/10 /2020

\section{Doctorando:}

\section{Facundo Ismael Casasola}

Facultad de Ingeniería del Ejército, Universidad de la Defensa Nacional, Ciudad de Buenos Aires, República Argentina. Universidad Tecnológica Nacional, Regional Buenos Aires, Ciudad de Buenos Aires, República Argentina.

facundoicasasola@gmail.com

\section{Directora:}

\section{Lidia Ana Otero}

\section{Resumen}

Durante el mes de agosto de 2020, se presentaron en la provincia de Córdoba numerosos focos de incendios que derivaron en la pérdida de más de 80 mil hectáreas de bosques nativos. El presente trabajo tiene la finalidad de describir cómo el empleo de la información espectral de sensores remotos satelitales NOAA, MODIS, VIIRS, Landsat 8 y Sentinel 2 y 3 ofrecen la posibilidad de brindar recursos técnicos para el seguimiento "quasi real time" de la evolución e impacto en este tipo de emergencias.

Los incendios forestales son una de las mayores causas de problemas ambientales y ecológicos en muchas partes del mundo. En la Argentina anualmente provocan la destrucción de miles de hectáreas de bosques nativos y otros tipos de vegetación. También consumen valiosos recursos económicos, generan un inmenso daño económico y alteraciones significativas de los ecosistemas, siendo una de las principales causas de la transformación de la cubierta terrestre.

Palabras clave: incendios forestales, sensado remoto, emergencias

\section{Abstract}

During August 2020 several fire sources in the province of Córdoba caused the loss of more than 80 thousand hectares of native forests. The purpose of this paper is to describe how spectral information from NOAA's remote satellite sensors such as MODIS, VIIRS, Landsat 8 and Sentinel 2 and 3 can provide technical resources for "quasi real time" monitoring of the evolution and impact on these kind of emergencies.

Wildfires are one of the biggest sources of environmental and ecological issues worldwide. In Argentina they cause the annual loss of thousands of hectares of native forests and other types of vegetation. They also destroy valuable economic resources, generating an immense economic damage and modifying significantly the ecosystems, being one of the main causes of land cover transformation. 
Keywords: wildfires, remote sensing, emergencies.

\section{Introducción.}

Los incendios forestales son un importante factor de transformación ambiental para una amplia variedad de ecosistemas mundiales (FAO, 2006). En la actualidad el empleo de los sensores remotos facilitan el monitoreo y visualización de áreas de incendios, su detección y comportamiento. Permitiendo apreciar en detalle sus causas, su desarrollo y las consecuencias que provocan. El presente artículo tiene la finalidad de describir como el empleo de la información espectral de las imágenes satelitales ofrecen la posibilidad de obtener una visión macro y local de las áreas afectadas por los incendios.

El análisis multiespectral permite determinar el combustible potencial de masas forestales, identificar zonas afectadas por incendios o visualizar los frentes de fuego a lo largo del tiempo. Las imágenes propuestas para realizar un análisis de incendio son aquellas que poseen canales centradas en las longitudes de onda del rojo (RED - 0,618 / 0,78 $\mu \mathrm{m}$ ), infrarrojo cercano (NIR - 0,7 / 0,87 $\mu \mathrm{m}$ ) e infrarrojo de onda corta (SWIR - 1,6 / 2,2 $\mu \mathrm{m}$ ).

Este trabajo propone una metodología para la visualización de superficies con vegetación quemada mediante la generación de imágenes RGB Falso Color y el cálculo de las superficies afectadas por los incendios forestales derivada de la vectorización de los pixeles georreferenciados de una imagen que muestre un índice normalizado de áreas quemadas (NBR Normalized Burn Ratio).

\section{Aspectos a considera para la elección de imágenes.}

Es importante entender que el seguimiento de los incendios con imágenes además de observar el aspecto espectral debe responder a una variable temporal adecuada que permita distinguir el comportamiento permanente de la dispersión de los fuegos como también una visión espacial que cubra aspectos a nivel regional y local. Es aquí el desafío de entender que las imágenes tienen que equilibrar aspectos relacionados a su resolución espacial, temporal y espectral.

Durante los incendios ocurridos en la provincia de Córdoba en el mes de agosto de 2020 se emplearon imágenes MODIS/Terra, MODIS/Aqua, VIIRS y Sentinel 3 para seguimiento diario a nivel regional e imágenes Sentinel 2 MSI y Landsat 8 OLI TIRS para visualizar comportamientos locales (Tabla 1).

En este estudio se describe lo acontecido en proximidades a la localidad de Villa Albertina, donde se presentó el foco de incendio más importante, sector donde los fuegos perduraron durante 10 días.

Para la estimación de las áreas afectadas por los incendios se procedió a la elección, calibración radiométrica y corrección geométrica de las imágenes multiespectrales anteriormente señaladas. Luego, con el empleo de un índice normalizado de áreas quemadas se derivó a generar los polígonos que describieran el impacto espacial de la zona.

Teniendo presente que la firma espectral de la vegetación sana muestra elevados niveles de reflectividad en el NIR descendiendo bruscamente hacia el SWIR y por el contrario, la vegetación afectada por un incendio adquiere un comportamiento opuesto mostrando bajos niveles de reflectividad en el NIR y en ascenso hacia el SWIR en los frentes de incendio. La vegetación viva es muy reflectiva en la banda del NIR y no tanto en la del SWIR, mientras que la que ha sufrido daños tiene cada vez valores de reflectividad más bajos en la banda del NIR y más altos en la del SWIR. 


\section{Descripción técnica de los sensores.}

\begin{tabular}{|c|c|c|c|c|c|c|}
\hline Sensor & $\begin{array}{c}\text { Resolución } \\
\text { Espacial }\end{array}$ & \multicolumn{2}{|c|}{ Resolución Espectral } & $\begin{array}{c}\text { Resolución Temporal } \\
\text { (Revisita) }\end{array}$ & $\begin{array}{l}\text { Agencia } \\
\text { Espacial }\end{array}$ & Bandas empleadas \\
\hline \multirow{3}{*}{$\begin{array}{l}\text { MODIS (Moderate } \\
\text { Resolution Imaging } \\
\text { Spectroradiometer) }\end{array}$} & $250 \mathrm{~m}$ & $\mathrm{~B} 1-\mathrm{B} 2$ & \multirow{3}{*}{$0,4 / 14,4 \mu \mathrm{m}$} & Diaria & \multirow{3}{*}{ NASA } & B7 (2105 / 2155 nm) \\
\hline & $500 \mathrm{~m}$ & B3 - B7 & & (Terra 1400 UTC Aprox) & & B2 $(841$ / 876 nm) \\
\hline & $1 \mathrm{~km}$ & $\mathrm{~B} 8-\mathrm{B} 36$ & & (Aqua 1730 UTC Aprox) & & $\mathrm{B} 1(620 / 670 \mathrm{~nm})$ \\
\hline \multirow{3}{*}{$\begin{array}{l}\text { VIIRS (Visible Infrared } \\
\text { Imaging Radiometer } \\
\text { Suite) }\end{array}$} & 750 m Nadir & Bandas M & \multirow{3}{*}{$0,412 / 12,01 \mu \mathrm{m}$} & \multirow{3}{*}{$\begin{array}{c}\text { Diaria } \\
\text { (S-NPP } 1730 \text { UTC Aprox) } \\
\text { (NOAA-20 } 1820 \text { UTC Aprox) }\end{array}$} & \multirow{3}{*}{ NASA } & $\mathrm{M} 11(2.225-2.275 \mu \mathrm{m})$ \\
\hline & $375 \mathrm{~m}$ Nadir & Bandas I & & & & $\mathrm{I} 2(0,846-0,885 \mu \mathrm{m})$ \\
\hline & 750 m Nadir & $\begin{array}{l}\text { Banda Pan } \\
\text { D/N }\end{array}$ & & & & I1 $(0,600-0,680 \mu \mathrm{m})$ \\
\hline \multirow[b]{2}{*}{ Sentinel $3 \mathrm{OLCl}$} & $300 \mathrm{~m}$ & \multirow{2}{*}{\multicolumn{2}{|c|}{$\begin{array}{c}21 \text { Bandas espectrales } \\
400-1020 \mathrm{~nm}\end{array}$}} & & & Oa04 (490 nm) \\
\hline & $1,2 \mathrm{~km}$ & & & Diaria & $\mathrm{e}_{\mathrm{sa}}$ & $\begin{array}{l}\text { Oa06 }(560 \mathrm{~nm}) \\
\text { Oa08 }(665 \mathrm{~nm})\end{array}$ \\
\hline \multirow{6}{*}{ Sentinel $2 \mathrm{MSI}$} & \multirow{2}{*}{$10 m$} & $\mathrm{~B} 2$ - B4, & $492,4 / 664,6 \mathrm{~nm}$ & \multirow{6}{*}{ 5/6 días } & \multirow{6}{*}{$\mathrm{e}_{\mathrm{sa}}$} & B2 $(492,4 \mathrm{~nm})$ \\
\hline & & B8 & $838,8 \mathrm{~nm}$ & & & B3 $(559,8 \mathrm{~nm})$ \\
\hline & 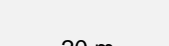 & $\mathrm{B} 5-\mathrm{B} 8 \mathrm{a}$ & $704,1 / 864,7 \mathrm{~nm}$ & & & B4 $(664,6 \mathrm{~nm})$ \\
\hline & 20111 & $\mathrm{~B} 11-\mathrm{B} 12$ & 1613,7 / 2202,4 nm & & & B5 $(704,1 \mathrm{~nm})$ \\
\hline & & B1 & $442,7 \mathrm{~nm}$ & & & B8 $(832,8 \mathrm{~nm})$ \\
\hline & $60 \mathrm{~m}$ & $\mathrm{~B} 9-\mathrm{B} 10$ & $945,1-3173,5 \mathrm{~nm}$ & & & B12 $(2020,4$ nm) \\
\hline \multirow{5}{*}{ Landsat 8 OLI TIRS } & $15 \mathrm{~m}$ & B8 & $0,503-0,676 \mu \mathrm{m}$ & \multirow{5}{*}{16 días } & \multirow{5}{*}{$\begin{array}{l}\text { USGS - } \\
\text { NASA }\end{array}$} & B2 $(0,452-0512 \mu \mathrm{m})$ \\
\hline & \multirow{3}{*}{$30 \mathrm{~m}$} & $\mathrm{~B} 1-\mathrm{B} 6$ & $0,435-1,651 \mu \mathrm{m}$ & & & B3 $(0,533-0,590 \mu \mathrm{m})$ \\
\hline & & B7 & $2,107-2,294 \mu \mathrm{m}$ & & & B4 $(0,636-0,673 \mu \mathrm{m})$ \\
\hline & & B9 & $1,363-1,384 \mu \mathrm{m}$ & & & B5 $(0,851-0,879 \mu \mathrm{m})$ \\
\hline & $100 \mathrm{~m}$ & $\mathrm{~B} 10-\mathrm{B} 11$ & $10,6-12,51 \mu \mathrm{m}$ & & & B7 $(2,107-2,294 \mu \mathrm{m})$ \\
\hline
\end{tabular}

Tabla 1 - Descripción de Sensores Remotos empleados para el seguimiento de incendios forestales en la provincia de Córdoba.

\section{Seguimiento de los incendios.}

El primer recurso empleado para visualizar las áreas afectadas por los incendios en la localidad de Villa Albertina, provincia de Córdoba fueron las imágenes MODIS Terra, MODIS Aqua VIIRS, empleando la resolución espacial para generar una imagen RGB Falso Color colocando en el canal rojo, verde y azul las bandas centradas en infrarrojo cercano, infrarrojo de onda corta y rojo respectivamente (Figura 1).

En segundo lugar, se descargaron imágenes Sentinel 2 y Landsat 8 de las zonas más afectadas. A estas imágenes se les realizó geoprocesos para dejar las matrices a emplear con el mismo tamaño de pixel (resampleo) y para definir un sistema de referencia y coordenadas eligiendo el sistema EPSG ${ }^{1} 4326$ que define coordenadas geográficas con el elipsoide WGS 84. A diferencia de las imágenes mencionadas en el párrafo precedente, las imágenes Sentinel 2 y Landsat 8 tienen pixeles que representan 10 y 30 metros sobre la superficie terrestre, lo que permite un cálculo más preciso de las dimensiones afectadas por los incendios (Figura 2).

\footnotetext{
${ }^{1}$ European Petroleum Survey Group, Código para definir el sistema de referencia de coordenadas.
} 


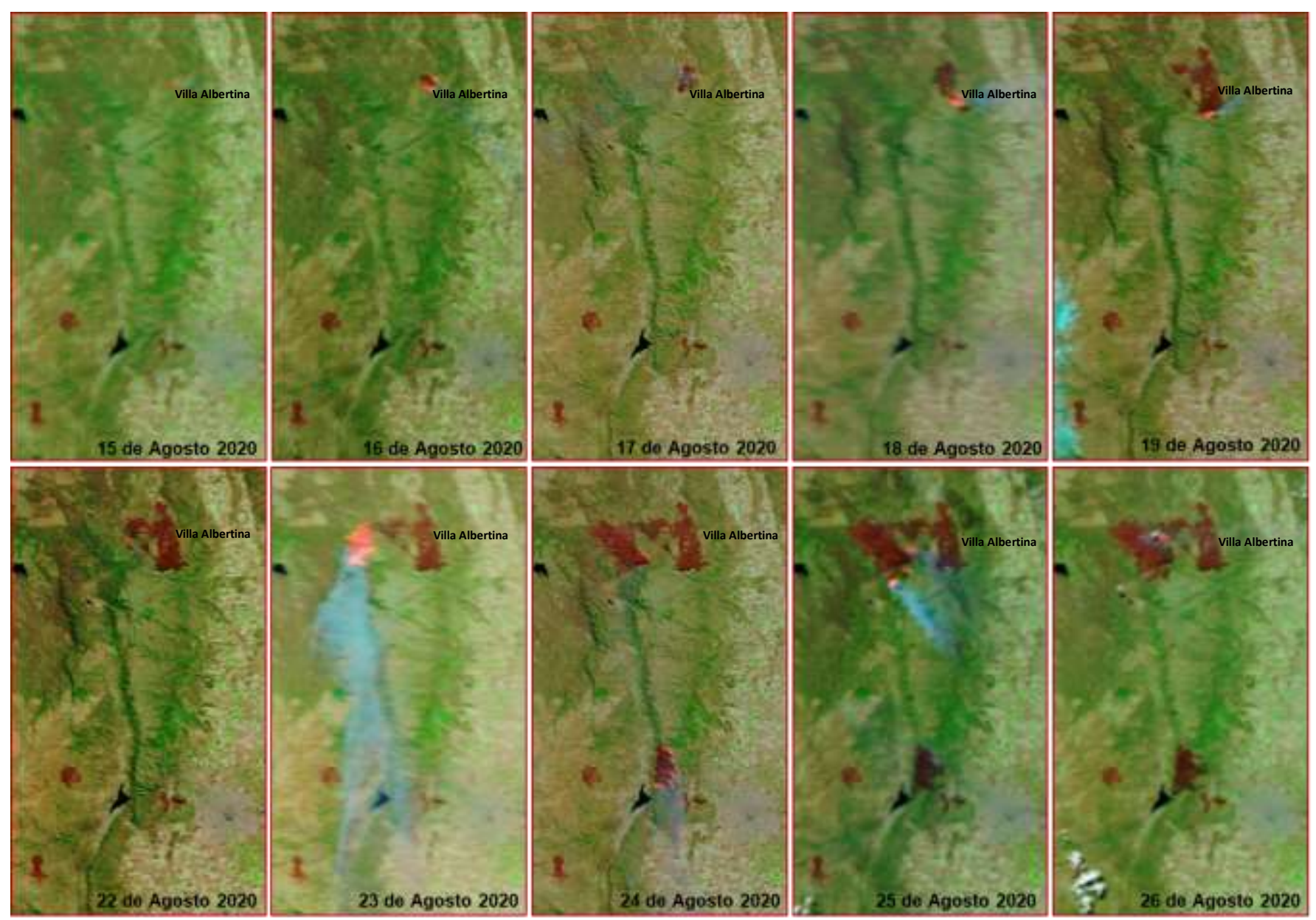

Figura 1 - Imágenes Falso Color (SWIR-NIR-RED) de los incendios en la provincia de Córdoba Sensor MODIS Terra, Agencia Espacial NASA.

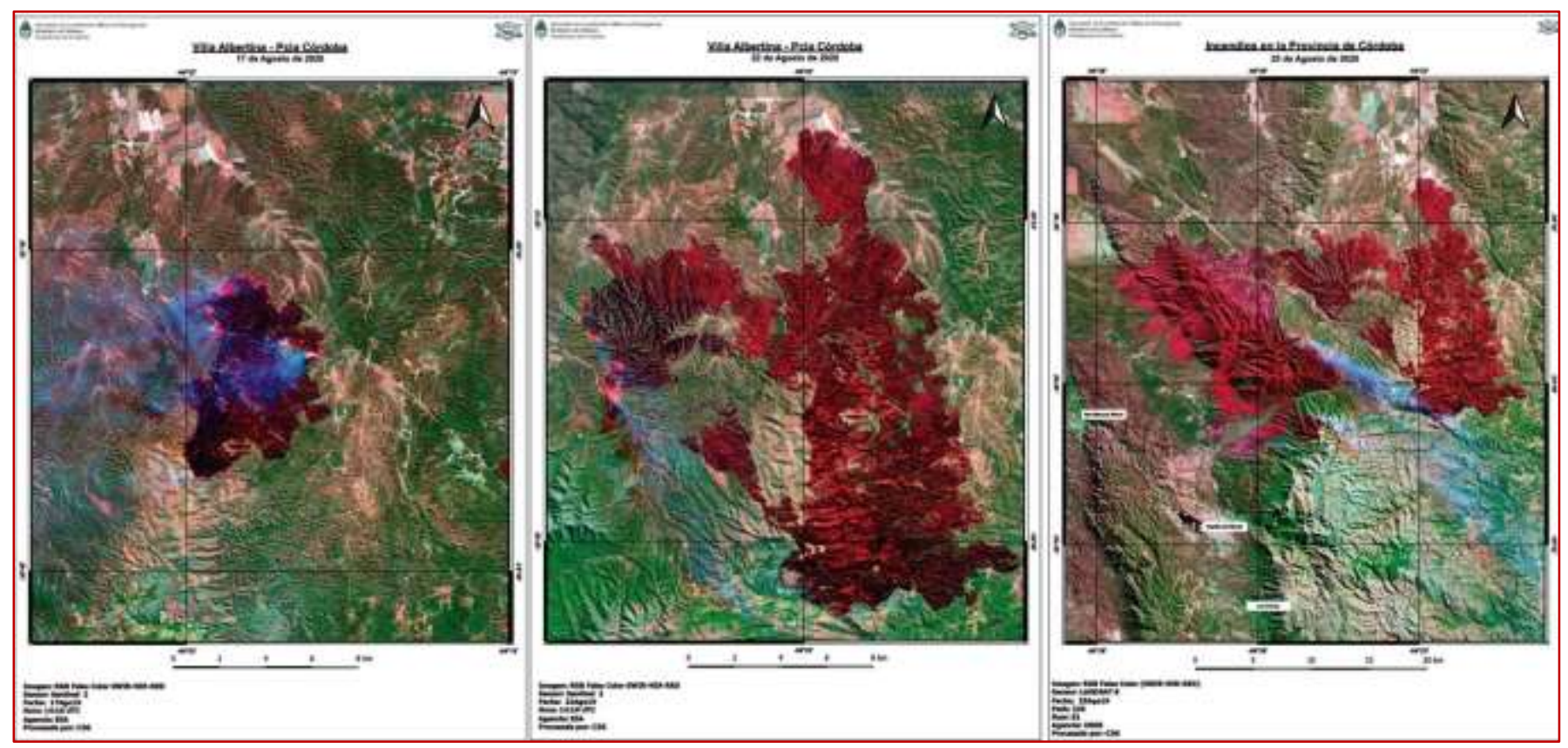

Figura 2 -Imágenes Falso Color (SWIR-NIR-RED) de los incendios en la provincia de Córdoba Sensor Sentinel 2 (ESA) y Landsat 8 (USGS/NASA). 


\section{Estimación de Áreas quemadas.}

Como se mencionó con anterioridad, la vegetación viva es reflectiva en la banda del NIR y no tanto en la del SWIR, mientras que la que ha sufrido daños tiene cada vez valores de reflectividad más bajos en la banda del NIR y más altos en la del SWIR. De esta forma, la manera simple y clásica para evaluar el área quemada y la severidad del incendio es calcular el índice NBR ${ }^{2}$ (Keeley, 2009) y asociar valores bajos del índice con alta severidad.

El resultado se produce al dividir la diferencia de reflectancia de las bandas del NIR y SWIR con la suma de las mismas bandas.

\section{((NIR-SWIR)) / ((NIR+SWIR))}

Una manera de evaluar áreas quemadas, es comparar el NBR de dos imágenes: una anterior y otra posterior al incendio. De esta manera se evita tener que preocuparse de las superficies que no son área quemada y que sin embargo tienen un bajo NBR (como suelos desnudos, caminos y ciertas superficies brillantes), para centrarse sólo en las superficies que han cambiado tras el incendio. A este índice se le denomina diferencia de índice normalizado de áreas quemadas (dNBR) (Alexander, 2006).

\section{dNBR $=$ NBR pre - NBR post}

Este diferencial varía aproximadamente entre $-0,5$ y +1,3 (donde los valores más negativos indican vegetación regenerada, los valores entre -1 y $+0,99$ zonas no quemadas y los valores más positivos zonas afectadas, aumentando con la severidad de los daños).

Teniendo presente lo descripto, se procedió a generar imágenes sintéticas del índice NBR con las imágenes de mejor resolución espacial (Sentinel $2 \mathrm{MSI}$ ), se calcula además la respuesta espectral de cada imagen (Figura 3). Luego, se generan en virtud al rango radiométrico de áreas dañadas definido por NBR las máscaras vectoriales (MV) cuyos polígonos representan cuantitativamente las superficies quemadas (Figura 4).

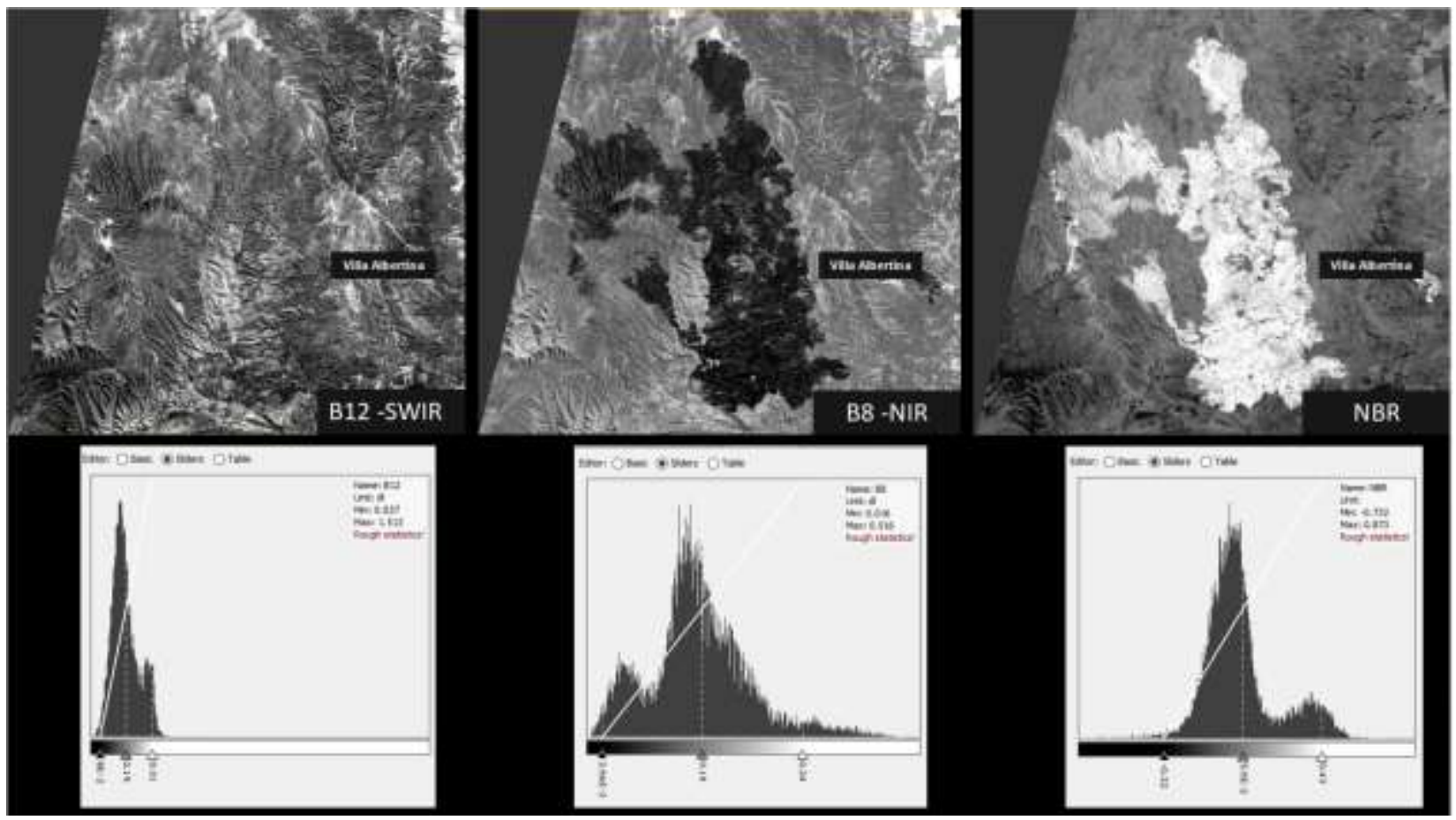

Figura 3 - Imágenes de la respuesta espectral de las bandas del SWIR, NIR y NBR.

\footnotetext{
${ }^{2}$ Normalized Burn Ratio, El índice de quemado normalizado (NBR) es un índice diseñado para resaltar áreas quemadas en grandes zonas de incendio.
} 


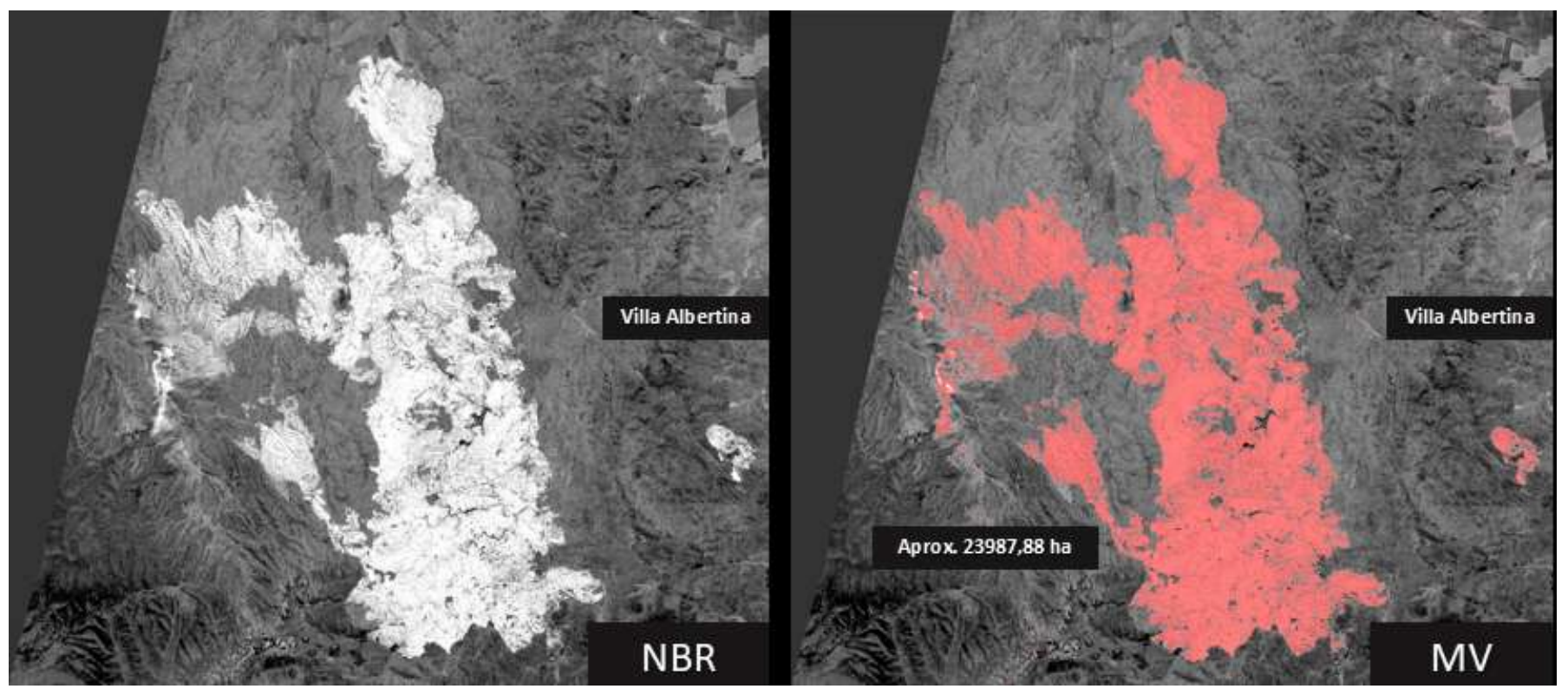

Figura 4 - Máscara Vectorial para la estimación del área quemada.

Del proceso empleado, se pudo estimar que en el trascurso de los 10 días dónde los incendios forestales permanecieron activos, se consumieron aproximadamente 24 mil hectáreas de bosque nativo.

\section{Conclusiones.}

1. El empleo de la información espectral de las imágenes satelitales facilita el análisis y visualización de diversos eventos adversos que suceden recurrentemente en nuestro territorio. La posibilidad de contar con productos que respondan de manera oportuna a este tipo de incidente, brindan un panorama general del desarrollo de lo que acontece.

Esta visión permite:

a. Identificar sectores o zonas más afectadas.

b. Interpretar el comportamiento del evento.

c. Observar limitaciones provocadas por la topografía o variables del ordenamiento territorial.

d. Priorizar la designación de recursos humanos y materiales a las áreas afectadas.

2. El empleo del índice NBR ofrece la posibilidad de estimar de manera operativa áreas quemadas, otorgando un recurso para una primera apreciación del impacto ambiental del escenario afectado. No obstante, es importante entender que la apreciación que brinda el índice responde de manera directa al tamaño del pixel de la imagen multiespectral empleada, por tal motivo como parte del trabajo de investigación se prevee comparar el resultado ofrecidos por las imágenes cuyos pixeles poseen una resolución espacial entre 250/500 m y aquellas imágenes de 10/30 m, para obtener el error relativo que pueden devolver la estimación de las imágenes con una mayor resolución espacial.

\section{Referencias}

Alexander, A. (2006). Manejo de incendios forestales mediante teledetección. Research Gate.

FAO. (2006). Fire management - global assesment . FAO Forestry Papers, 151.

Keeley, J. (2009). Fire intensity, fire severity and burn severity: A brief review and suggested usage. ReseachGate, 116-126. 